\title{
Spatial Patterns of African-American Population and Movement in Chicagoland
}

\author{
Robert Hunley \\ Tekleab Gala \\ Department of Geography \\ Chicago State University \\ 321 William Science Building \\ 9501 S King Dr, Chicago \\ IL 60628 USA
}

\begin{abstract}
Although world's and US's population are steadily growing, Chicagoland's is population is either growing slowly or negatively and African Americans are leading this sluggish or diminishing trend. This study used census data to investigate spatial-resolved African American population movement at the scale of census tract. Accordingly, significant settlement patterns and movement were discovered, such that $48 \%$ of the city's community areas and $21 \%$ of Suburban municipalities have shown a cluster of high percent African American population. On the other hand, significant clustering (i.e., $p>0.05$ ) of lower African American population was detected in 39\% community areas and $51 \%$ of the suburban municipalities. Additionally, the 2010 population patterns have shown changes from the 1990s, such that net loss was observed in 51\% of the city's community areas, and net gains in 75\% of the suburban municipalities (i.e., $p>0.05$ ); indicating a clear African Americans' urban-to-suburban movement.
\end{abstract}

Keywords: Population Movement, Urban-to-Suburban migration, Segregation, African American, and Chicagoland.

\section{Introduction}

The world population has been growing, although the trend has been consistent throughout the history. According to the world population clock, only 5 million people were approximated to have lived around $8000 \mathrm{BC}$ and around $1 \mathrm{AD}$, the population grew to 200 million indicating a growth rate of only $0.05 \%$. The world population started picking-up at an exponential rate following the industrial revolution [1]. For instances. while it had taken 1800 years for the world population to become a billion, it took only in less than 150 years to top 5 billion at an approximately $2 \%$ annual growth rate. With the current growth rate of $1.11 \%$, the world population is expected to grow and become 10 billion in $2056[2]$.

The population trend of the United States is not any different from the global. U.S. had a population of approximately 76 million in 1900 and 160 million in 1950s, which over the past 77 years, the population had increased by almost 115\%. The annual growth rate was picked at $1.8 \%$ in 1956 and reduced to $0.88 \%$ in 1970s. In 1998, a slight increase in the growth rate (i.e., 1.26\%) was noted and currently the rate stands at $0.73 \%$. According to U.S. Census Bureau [3], the US population stands $323,148,587$ million people, is the third most populous country on earth. With this growth rate, the U.S. population is projected to reach 417 million, increased by 98.1 million, from the estimate of 2014.

Chicago Metropolitan Area, often referred to Chicagoland, has nearly 9.9 million people, making it the third-largest MSA (Metropolitan Statistical Area) in the United States and the largest in the Midwestern United States. However, unlike global and national population trends, the metropolitan area population is either growing slowly [4] or losing [5]. According to Population Change and Geographic Mobility in the CMAP Region (2015), the population of the Chicago metropolitan area is growing slower at a rate of $0.9 \%$; the rate that is lagging behind other metropolitan areas. For example, of the top-ten metro areas in the U.S., Chicago ranks the bottom in overall rate of population growth. Similarly, of the 52 U.S. metros with population over 1 million residents, Chicago's $0.9 \%$ population growth rate ranks 44th. On the other hand, Eltagouri [5] reported Chicago as the only city among the nation's twenty largest cities to experiencing population loss. According to Eltagouri [5], between 2014 and 2016, the city of Chicago has lost about 2,890 residents; while the city and suburb areas together lost an estimated 6,263 residents, the greatest loss of any metropolitan area in the country. Black Chicagoan's are among the prime demographic category calling it quits on their hometown. Using the census data of 2000 and 2010, Eltagouri, [5], reported that Chicago has lost 181,000 African American residents between 2000 and 2010. Since 2010, Chicago metropolitan area have further lost 46,000 African American residents [6]. African Americans are quitting in search for better economic opportunities, and safer neighbourhoods, with many heading to the suburbs and/or southern warm states. 
Therefore, the objective of this study was to use geospatial techniques for establishing spatially-resolved settlement pattern of African American Population and movement within the metropolitan area of Chicago. There is hypothesized urban-to-rural African American population movement, which if establish, have implications on our understanding of impacts on population diversity, opportunities, resources sharing and the environment.

\section{A. Research Data And Methodology}

\section{B. Study Area}

Chicago Metropolitan Area, often referred to as Chicagoland, has nearly ten million (9.9 million) people, making it the third-largest MSA (Metropolitan Statistical Area) in the United States. The metropolitan area that includes Cook, DuPage, McHenry, DeKalb, Lake, Kane, Kendall, Will, Grundy, and Kankakee Counties in Illinois; Kenosha County of Wisconsin; and Lake and Porter Counties of north-western Indiana; linked to the city through geographic, social, economic and cultural ties. Cook County is the seat of Chicago and is the second-most populous county in the United States after Los Angeles County, CA. It is also where more than $40 \%$ of all residents of Illinois live. Cook County is considered in this study due to its large population of African-Americans (Figure 1). Out of the 5,180,493 population estimate of the county, approximately 1,243,319 (i.e., 24\%) are African Americans, which is almost twice the rate of the State of Illinois and the nation.

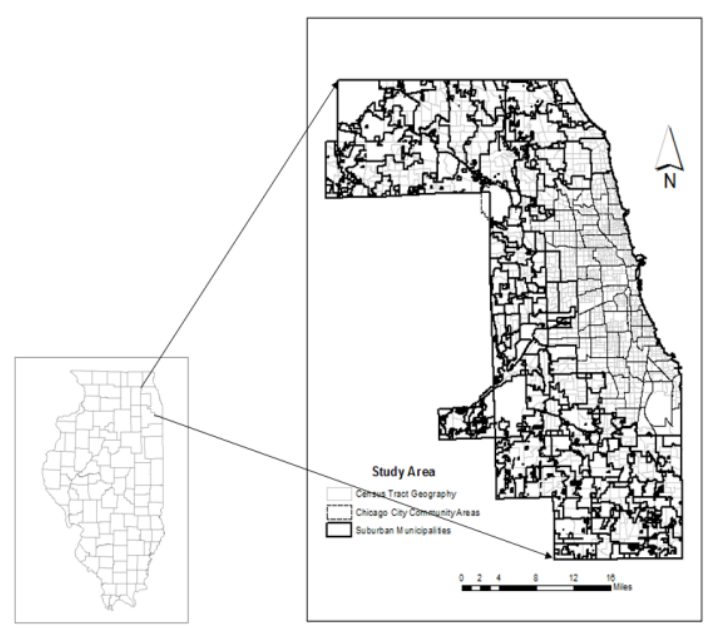

Fig 1: Study area: Community areas of Chicago city and the surrounding suburban municipalities

\section{Research Data}

This study used census data of 1990 and 2010. A census data is an information that is systematically acquires the records of every member of the U.S. population. The U.S. Census Bureau collects records of demographic, socioeconomic and housing characteristics of the residents; pre-processes and makes available at various spatial scales in a quality-usable directly by university researchers, businesses, marketing and local government planning. This study used the data aggregated at a prominent census geography known as "tract". The boundary shapefiles corresponding to the census tract was acquired from Census Tiger/Line files. A GIS attribute table formatting operation was conducted for spatial joining census demographic data with its corresponding census geography. Even though, the data analyses were conducted at the scale of census tract, the result was presented and interpreted at the scale of community areas and suburban municipalities for the planning and policy implications. For example, municipalities are local functional units of the government for the purpose of providing various utilities and services for the population; whereas, Community Areas were defined by University of Chicago's Social Science research committee for the city's statistical and planning purpose. Hence, shapefiles for 117 suburban municipalities and the Chicago's 77 community areas were obtained from the City of Chicago's GIS data portal.

\section{Data Analysis}

\section{a) Spatial analysis of African American Population Distribution in Chicago Metropolitan Area:}

\section{Geovisualization}

The spatial analysis of the settlement pattern and movement of African American population in Chicago city and surrounding municipalities was evaluated visually using a quantitative Choropleth mapping. Such map is the most 
common data mapping technique that has the ability to communicate the distribution, and magnitude of changes in space. It uses a graduated color shade to represent quantitative information by grouping the population into classes. For example, values of percent African American population was grouped into 5 classes namely: very low (i.e., 5\% and below), low (i.e., $5 \%-10 \%)$, about state's or nation's average (i.e., $10 \%-20 \%)$, about the county's average $(20 \%$ $40 \%$ ) and dominant (i.e., $40 \%-100 \%$ ).

\section{Global Moran's I}

Moran's I coefficient is the most commonly used geostatistical used for analysing whether census's percent African American population at nearby census tracts are may be more similar than African American population made at census tracts farther apart. It is a test of the first law of geography, which states that values of measurement at nearby locations are more correlated. Geostatistical analysis of the spatial pattern of African American population distribution was analysed using Global Moran's I. Global Moran's I is estimated by Moran's I index $\{7,8]$ expressed as:

$$
I=\frac{n}{s_{0}} \frac{\sum_{i=1}^{n} \sum_{j=1}^{n} w_{i j} z_{i} z_{j}}{\sum_{i=1}^{n} z_{i}^{2}}
$$

Where: $\mathrm{Zi}$ is the deviation of an percent African American population for census tract $\mathrm{i}$ from its mean $(\mathrm{x}-\mathrm{x} \overline{)}$, Wi,j is the spatial weight matrix between features $i$ and $j, n$ is equal to the total number of census tracts, and So is the aggregate of all spatial weight:

$$
S_{o}=\sum_{i=1}^{n} \sum_{j=1}^{n} w_{i, j}
$$

The $\mathrm{Zi}$-score for the statistic is computed as:

$$
Z_{I}=\sqrt{\frac{I-E[I]}{V[I]}}
$$

Where:

$$
\begin{aligned}
& E[I]=-1 /(n-1) \ldots \ldots \ldots \ldots \ldots \ldots(4) \\
& V[I]=E\left[I^{2}\right]-E[I]^{2} \ldots \ldots \ldots \ldots \ldots \ldots(5) \\
& E\left[I^{2}\right]=\frac{A-B}{C} \ldots \ldots \ldots \ldots \ldots \ldots \ldots \ldots(6) \\
& \left.A=n\left\lceil\left(n^{2}-3 n+3\right) S_{1}-n S_{2}+3 S_{0}^{2}\right)\right] \\
& B=D\left[\left(n^{2}-n\right) S_{1}-2 n S_{2}+6 S_{0}^{2}\right] \ldots .(8) \\
& C=(n-1)(n-2)(n-3) S_{0}^{2} \ldots \ldots \ldots(9) \\
& D=\frac{\sum_{i=i}^{n} z_{i}^{4}}{\left(\sum_{i=i}^{n} z_{i}^{2}\right)^{2} \ldots \ldots \ldots \ldots \ldots \ldots \ldots . . \ldots(10)} \\
& S_{1}=(1 / 2) \sum_{i=1}^{n} \sum_{j=1}^{n}\left(w_{i, j}+w_{j i}\right)^{2} .(11) \\
& \text { Local Moran's I }
\end{aligned}
$$

\section{Local Moran's I}

Local Moran's I analyse the above spatial dependency (correlation) at local level, i.e., local indicator of spatial relationships of the percent African American population in Chicago and its surrounding suburbs. The analysis, also known as Getis-Ord Gi* Statistic, given a set of weighted distance relations, identifies statistically significant local relationship of high values of percentage African American population, vis-à-vis relationship of values. The standard tool used for examining Getis-Ord Gi* Statistic (I) and expressed as [9]:

$$
I_{i}=\frac{x_{i}-\bar{x}}{s_{i}^{2}} \sum_{j=1, j \neq i}^{n} W_{i, j}\left(x_{i}-\bar{X}\right) \ldots
$$

Where: $\mathrm{Xi}$ is an attribute for feature $\mathrm{i}, \mathrm{X}$ is the mean of the corresponding attribute , Wi,j, is spatial weight between feature $i$ and $j$ and: 


$$
S_{i}^{2}=\frac{\sum_{j=1 j \neq i}^{n} W_{i f}}{n-1}-\bar{X}^{2}
$$

With $\mathrm{n}$ equating to the total number of features. The $\mathrm{Z}_{\mathrm{ii}}$ - score for the statistics were computed as:

$$
Z_{I i}=\frac{I_{i}-E\left[I_{i}\right]}{\sqrt{V\left[I_{i}\right]}}
$$

Where:

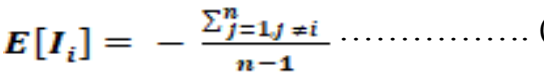

$$
\begin{aligned}
& \boldsymbol{V}\left[\boldsymbol{I}_{i}\right]=\boldsymbol{E}\left[\boldsymbol{I}_{i}^{2}\right]-\boldsymbol{E}\left[\boldsymbol{I}_{i}\right]^{2} \\
& E\left[I^{2}\right]=A-B \\
& A=\frac{\left(n-b_{2 i}\right) \sum_{j=1 j \neq i}^{n} W_{i f}^{2}}{n-1} \\
& \boldsymbol{B}=\frac{\left(2 b_{2 i}-n\right) \sum_{k=1 k \neq i}^{n} \sum_{h=1 \hbar \neq} W_{i, k} W_{i h}}{(n-1)(n-2)} . \\
& \boldsymbol{b}_{2 i}=\frac{\sum_{i=1 j \neq j}^{n}\left(x_{i}-X\right)^{4}}{\left(\sum_{i=1 j \neq j}^{n}\left(x_{i}-X\right)^{2}\right)^{2}} .
\end{aligned}
$$

\section{E. Change Analysis}

The study acquired the percentage as well as the population counts of African American at the scale of census tracts counties. The census data of 1990 and 2010 were used to see the changes and thereby to demonstrate the movement of African American population in Chicago and its surrounding suburban municipalities. African American population changes in the Chicago metropolitan area are mapped using a change map, which involved subtracting new values from the Old Value, then divide by the Old Value and multiply it by 100 is expressed as:

African American Population Change Map

$$
=\left[\frac{\text { Census data (2010) }- \text { Census data (1990) }}{\text { census data (1990) }}\right] * 100
$$

Change in percent African American population was grouped into 5 classes namely: high percent population loss (-50\% and more), intermediate loss (-10\% - - 50\%), no loss or gain (-10\%-10\%), intermediate African American population gain $(10 \%-50 \%)$ and high percent gain (50\% and above).

\section{F. Validation Methods}

Validation of the distribution and movement of African American were verified by the values of Moran's I Index and corresponding p-value. The values of Moran's I Index ranges between -1 and 1 and generally, while +1 Moran's Index value indicates a strong control of distance in spatial relationship of African American population distribution, the index nearing -1.0 indicates random distribution (i.e., no control). P-values ascertain statistical significance of the observed geographical settlement and change patterns. A high z-score and small p-value for a feature indicates a 
statistically significant spatial relationship of high percent or change in African American population, whereas a low negative z-score and small p-value indicates a spatial relationship among lower values of percent or change in African American population.

\section{Results}

\section{Spatial Analysis of African American Population Distribution in Chicago City and Surrounding Suburbs}

Figure 2 and Table 1 show distinct patterns of percent African-American distribution in Chicago and its surrounding suburban municipalities as per 2010 census data. Accordingly, 32 of the 77 community areas (i.e., 42\%) and 20 of 117 suburban municipalities (i.e., 24\%) have the dominant presence of African American population (i.e., greater than 40\%) (See Figure $2 \mathrm{a}$ and Table 1). However, statistically significant $(\alpha=0.05)$ clustering of census tracts with higher percent African American was detected in 38 community areas and 25 suburban municipalities (See Figure $2 b$ and Table 2). These census tracts are found in the south (e.g., Englewood, Chatham, Beverly, Washington Heights, South Deering, Pullman, Morgan Park, Hegewisch, Riverdale and South Chicago) and Westside (e.g., North Lawndale, West and East Garfield Park, Humboldt Park, and Austin) of the city. Examples of the suburban municipalities were Blue Island, Burnham, Calumet City, Calumet Park, Chicago Heights, Dixmoor, Dolton, East Hazel Crest, Evergreen Park, Flossmoor, Harvey, Hazel Crest and Homewood.
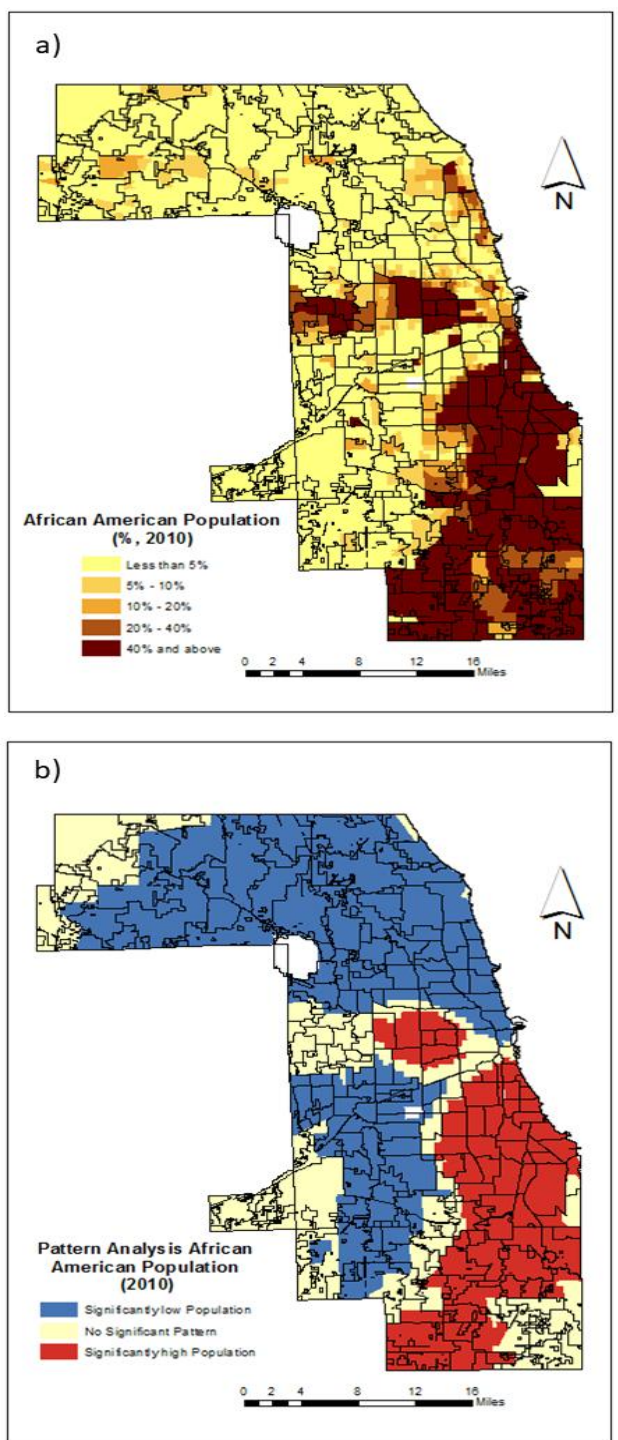

Fig 2: African American population settlement pattern in Chicago city and surrounding suburban municipalities: a) Percent African American distribution and b) Statistically significant geographical control of African American Population Distribution. Source U.S. Census Bureau 
On contrary, census tracts with very low percent African American population (i.e., less than 5\%) were observed in 32 of 77 (i.e., 42\%) community areas and 66 out of 117 (i.e., 55\%) suburban municipalities (See Figure 2a and Table 1). Thirty-one of the seventy-seven community areas (i.e., 39\%) and 61 of 117 suburban municipalities (i.e., 51\%) have shown a significant spatial clustering of low percent African American population $(\alpha=0.05)$ (See Figure $2 b$ and Table 2). Four of the 77 community areas (i.e., Archer Heights, Garfield Ridge, Gage Park and Clearing) are found in the southwestern side, while the majority (i.e., 27 or $87 \%$ ) are on the north and north western side of the city. Similarly, seven of these suburban municipalities were found in the north and north western parts; whereas the majority (i.e., 88\%) are found in the western and southwestern of the study area.

TABLE I

Number and Percent of Community areas and suburban municipalities in categories of African-American population distribution, 2010.

\begin{tabular}{|l|l|l|l|l|}
\hline \multirow{2}{*}{ Categories } & \multicolumn{2}{l|}{ Community Areas } & \multicolumn{2}{l|}{ Suburban municipalities } \\
\cline { 2 - 5 } & No. & $\%$ & No. & $\%$ \\
\hline$<=\mathbf{5}$ & 32 & 41 & 66 & 55 \\
\hline $\mathbf{5}-\mathbf{1 0}$ & 7 & 9 & 6 & 5 \\
\hline $\mathbf{1 0}-\mathbf{2 0}$ & 4 & 5 & 11 & 9 \\
\hline $\mathbf{2 0}-\mathbf{4 0}$ & 4 & 5 & 8 & 7 \\
\hline $\mathbf{4 0}-\mathbf{1 0 0}$ & 4 & 40 & 28 & 24 \\
\hline Sum & 32 & $\mathbf{1 0 0}$ & $\mathbf{1 1 7}$ & $\mathbf{1 0 0}$ \\
\hline
\end{tabular}

TABLE 2

Number and Percent of Community areas and suburban municipalities in categories of statistically significant cluster of African-American population distribution, 2010.

\begin{tabular}{|c|c|c|c|c|}
\hline Patterns of Clusters & 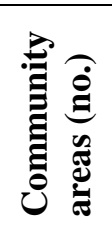 & 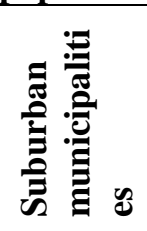 & 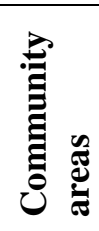 & 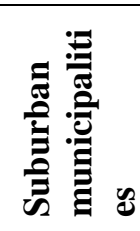 \\
\hline $\begin{array}{l}\text { Clustering of Significantly Lower } \\
\text { population }(\alpha=0.05)\end{array}$ & 31 & 61 & $39 \%$ & $52 \%$ \\
\hline No Significant Clustering $(\alpha=0.05)$ & 10 & 32 & $13 \%$ & $27 \%$ \\
\hline $\begin{array}{l}\text { Clustering of Significantly Higher } \\
\text { population }(\alpha=0.05)\end{array}$ & 36 & 24 & $48 \%$ & $21 \%$ \\
\hline Sum & 77 & 117 & 100 & 100 \\
\hline
\end{tabular}

Only census tracts in 4 of the 77 community areas (i.e., 5\%) and 11 out of 117 suburban municipalities (i.e., 9\%) have percent African American population about the state's average (i.e., 14.5\%) (See Figure 2a and Table 1). The community areas were: The Loop, Near West Side, Logan Square, Uptown, West Town and Rogers Park; while suburban municipalities such as Hoffman Estates in the northeast; Palos Hills, Chicago Ridge, and Evergreen Park in the southwest; and Homewood in the south. Generally, 64 of 77 (i.e., 81\%) of the community areas in Chicago had either high (i.e., > 40\%) or very low (i.e., <5\%) percent African American population, indicating a clear sign of racially segregated demographic landscape of the city (See Figure $2 \mathrm{~b}$ and Table 2).

A. Investigating African American Population Changes/Movement In Chicago City And Surrounding Suburban Municipalities Between 1990 And 2010

The 1990s census showed distinct historical settlement patterns of African American populations. Accordingly, census tracts in 31 community areas (i.e., 43\%) (i.e., Near West, West and South Sides) and 16 southern and western suburban municipalities i.e., (14\%) had dominant (i.e., greater than 40\%) African American population presence in the 1990s. Conversely, $42 \%$ and $68 \%$ of community areas of Chicago and suburban municipalities, respectively, in the northern, north-central, and southwestern part of the Chicago Metropolitan area had a lower presence of African American populations (i.e., less than 5\%). Census tracts in few community areas (i.e., 4\%) and suburban municipalities (i.e., 9\%) had African American populations at the state average (i.e., 14.5\%) (See Figure 3 and Table 3). 
The 2010 settlement pattern of African American population has shown a departure from the one in 1990 (See Figure 3, Table 1, and Table 3), although the majority of the census tracts in community areas and suburban municipalities have not experienced significant gain nor loss in African American population $(\alpha=0.05)$ (See Figure 4b, Table 4 and Table 5). Accordingly, not significant change was detected in 52 of the 72 community areas (i.e., $72 \%$ ) of Chicago and 89 out of 117 (i.e., 76\%) of the suburban municipalities. Most unchanged community areas were with very low (i.e., less than 5\%) and very high (i.e., above 40\%) percent African American population, indicating that not much has changed with regards to Chicago city's racially segregated settlement pattern over the 20 years (See Figure 4, Table 4 and Table 5). However, for Suburban municipalities, those with very low (i.e., less than 5\%) and low (i.e., 5\% - 10\%) percent African American population has slightly reduced by $19 \%$ and $17 \%$, respectively. Additionally, those with high (i.e., $20-40 \%$ ) and very high (i.e., $40 \%$ and above) percent African American population were also increased by $75 \%$ and $71 \%$; respectively, indicating movements of African American population into the suburban

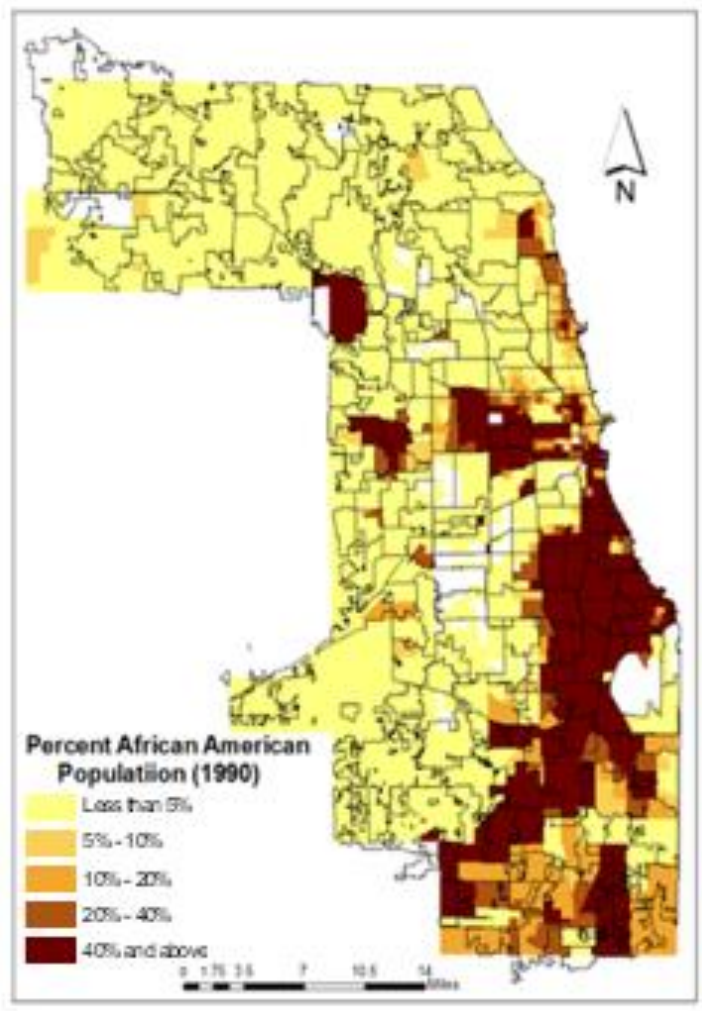

Fig 3: African American population settlement pattern in Chicago city and surrounding suburban municipalities in 1990

TABLE 3

Number and Percent of Community areas and suburban municipalities in categories of AfricanAmerican population distribution, 1990.

\begin{tabular}{|l|l|l|l|l|}
\hline \multirow{2}{*}{ Categories } & \multicolumn{2}{|l|}{ Community Areas } & \multicolumn{2}{l|}{ Suburban municipalities } \\
\cline { 2 - 5 } & No. & $\%$ & No. & $\%$ \\
\hline$<=\mathbf{5 \%}$ & 30 & 42 & 79 & 68 \\
\hline $\mathbf{5 \% - 1 0 \%}$ & 5 & 7 & 7 & 9 \\
\hline $\mathbf{1 0 \% - 2 0 \%}$ & 3 & 4 & 10 & 4 \\
\hline $\mathbf{2 0 \% - 4 0 \%}$ & 3 & 4 & 5 & 14 \\
\hline $\mathbf{4 0 \%}-\mathbf{1 0 0 \%}$ & 31 & 43 & 16 & 100 \\
\hline Sum & 72 & 100 & 117 & \\
\hline
\end{tabular}

However, significant gains observed, in 7 out of 72 community areas (10\%) and, 28 out of 117 (i.e., $75 \%$ ) suburban municipalities $(\alpha=0.05)$ (See Figure 4, Table 4 and Table 5). These are areas in the southwest, West (i.e., Garfield Ridge) and Northwest (i.e., Belmont-Cragin and Montclare) of Chicago, while suburban municipalities are located in the Central-south, West, Southwest and Northwest of the study area (Figure 4. 
On the other hand, the majority of loss (i.e., $-10 \%$ and more) in African-American population was observed in 41 of 72 community areas (51\%), although only 13 of the 72 community areas (i.e., 18\%) have significantly lost $(\alpha=0.05)$. None of the suburban municipalities has significantly lost the African American population during the study period.
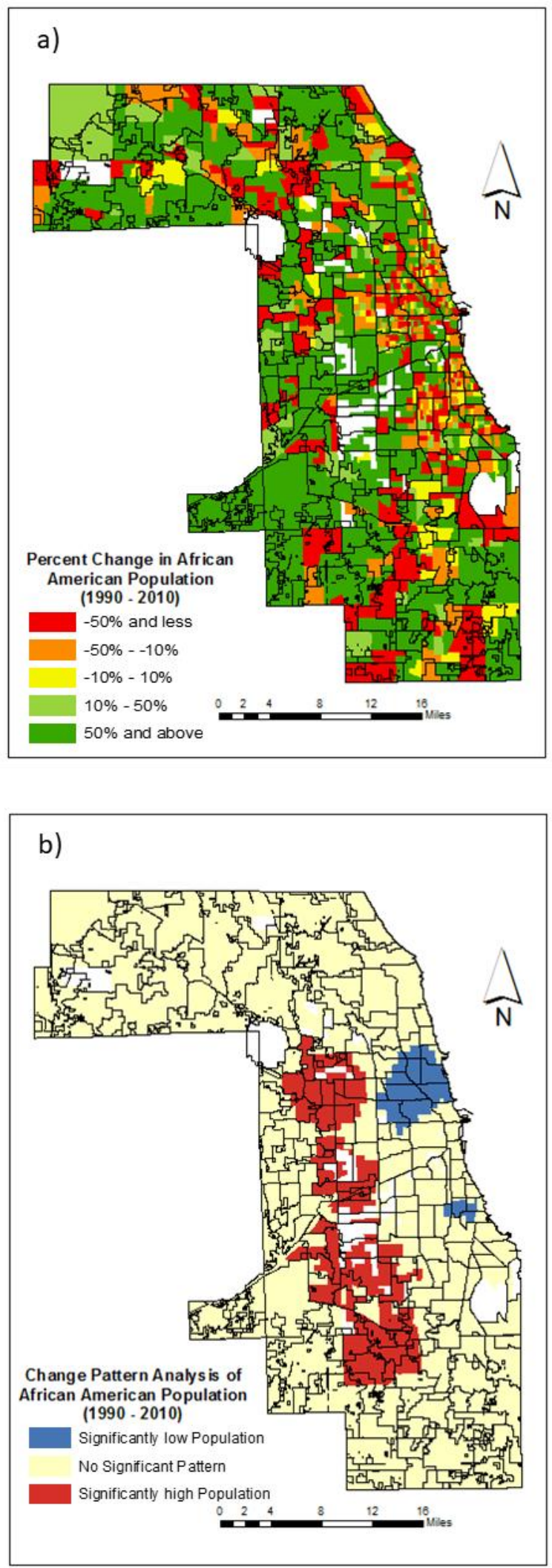
Fig 4: African American population changes and movement in Chicago and surrounding suburban municipalities (1990 and 2010): a) Percent change and b) significant geographic controls of change pattern

\section{Discussion}

Distinct spatial pattern of African American settlement is detected in Chicago and surrounding suburban municipalities. The pattern is such that dominant presence of African American population was observed in almost half of the community areas of Chicago city and a fifth of suburban municipalities. These are geographically located in the south and western part of the metropolitan area. On the other hands, low African American population settlement observed, again, in almost half of the community areas of the city and suburban, primary in the southwestern, north and northwestern parts of the study area. Such spatial arrangements depict a racially segregated demographic landscape of the metropolitan area. These spatial patterns are change from the ones in 1990, although it is not significant. Since 1990, approximately $3 / 4$ of the community areas and suburbans have experienced some sorts of African American population movements (i.e., gains or losses). A tens of the city's community areas (i.e., in the periphery) and a quarter of suburbans municipalities have shown significant gains, in percent African American population, indicating urban-tosuburban African American movement during the study period.

Racially segregated settlement patterns in Chicago city are legacies of the Great Migration, which brought about one million African Americans, a third of the city's population [10]. According to [10], the arriving African Americans settled on the South Side, stretching from 22nd street down to 55th street, which initially was labelled as "Black Belt of Chicago", although most African Americans call it "Bronzeville." Such localized and segregated settlement pattern was due to restrictive measures not to sale or lease properties to arriving African Americans elsewhere in the city. The discriminatory restriction could be from the Jim Crow laws, which enacted in the late 19th and early 20th to effect racial segregation in the United States. The law was challenged in 1940s but was effective until 1965, by then the segregation had taken its root making the country's third-largest city locally filled with singular races of two races.

Such racial segregation in cities have various impacts on African Americans and other minorities [11, 12]. According to [11], African Americans living in a segregated metropolitan area, like Chicagoland, have lower family income and scarce local opportunities. For example, there are, approximately 700,000 jobs within 40 minutes commute of Chicago downtown but only 50,000 jobs found within the same radius of Chicago south-side, where African American dominantly live [12]. Higher unemployment rate among African American in Chicagoland (16\% in 2018) reflects this phenomenon. The phenomenon, which created jobless neighbourhoods, the socio-economic disadvantages, particularly for youths, and unsafe and unstable community ravaged with cycle of violence [13]. Additionally, Poverty in the neighbourhoods are making black students to receive unequal learning opportunities [14]. According to [14] school funding in white neighbourhoods are 10 times bigger than the black neighbourhoods, and is having implications on the quality of teachers and curriculum offering and thence inferior educational attainment. The communities are also subjected of various forms of discrimination than those living in more integrated neighbourhoods.

TABLE 4

Number and Percent of Community areas and suburban municipalities in categories of AfricanAmerican population distribution, 2010.

\begin{tabular}{|c|c|c|c|c|}
\hline \multirow[t]{2}{*}{ Categories } & \multicolumn{2}{|c|}{ Community Areas } & \multicolumn{2}{|c|}{ Suburban municipalities } \\
\hline & No. & $\%$ & No. & $\%$ \\
\hline$<=-50 \%$ & 16 & 22 & 18 & 15 \\
\hline$-50 \%--10 \%$ & 21 & 29 & 7 & 6 \\
\hline$-10 \%-10 \%$ & 5 & 7 & 4 & 3 \\
\hline $10 \%-50 \%$ & 1 & 1 & 7 & 6 \\
\hline$>=50 \%$ & 29 & 40 & 81 & 69 \\
\hline Sum & 72 & 100 & 117 & 100 \\
\hline
\end{tabular}


TABLE 5

Number and Percent of Community areas and suburban municipalities in categories of statistically significant cluster of Gains and Losses in African American Population between 1990 and 2010.

\begin{tabular}{|l|l|l|l|l|}
\hline $\begin{array}{l}\text { Patterns of } \\
\text { Gains/Losses } \\
\text { Clusters }\end{array}$ & 13 & 0 & $18 \%$ & 0 \\
\hline $\begin{array}{l}\text { Clustering of } \\
\text { Significantly } \\
\text { Lower population } \\
(\alpha=0.05)\end{array}$ & 13 Significant \\
\hline $\begin{array}{l}\text { No } \\
\text { Clustering } \alpha \text {, } \\
0.05) \text { of }\end{array}$ & 52 & 89 & $72 \%$ & $76 \%$ \\
\hline $\begin{array}{l}\text { Clustering } \\
\text { Significantly } \\
\text { Higher population } \\
(\alpha=0.05)\end{array}$ & 7 & 28 & $10 \%$ & $24 \%$ \\
\hline Total & 72 & 117 & 100 & 100 \\
\hline
\end{tabular}

Generally, the urban-to-suburban movement of African American population corroborates previous reports [5, 12, 15]. According to [15], blacks are leaving cities and are becoming part of the demographic landscape of suburban USA. Chicago has lost an estimated 6,263 blacks' residents, which is the largest loss of any city in United States [5]. Similarly, Samuels, (2018) reported exodus of African American population from Chicago. According to [12], Chicago lost 181,000 black residents between 2000 and 2010. Increasing property values, gentrification, stable incomes and search for safer neighbourhoods were among the reasons indicated as to why blacks are deserting the city [1, 5, 12].

African Americans' urban-to-suburban movement is having various implications [12, 16]. First, since most black residents deserting the urban neighbourhoods are the middle-class families, the gap between rich and poor is exacerbated [5]. The departure of these families also made the neighbourhoods devoid of working families of highschool and/or college graduates, who could inspire, growing kids. On the other hands, urban-to-suburban migration is easing deeply entrenched pattern of segregation and enhancing racial integration. In fact, it is making Chicago metropolitan area, as one of the most diverse [17]. According to [17], Chicago's culturally and demographically segregated neighbourhoods are assuming a new integrated identity. Contemporary Chicago is revealing broad demographic diversity and multiculturalism with various academic, social and psychological advantages [18]. According to [18] racially integrated communities are tolerance and more engaging, strong workforces with higher achievement. The communities are likely to have reduced racial stereotypes and better cross-cultural understanding.

\section{Conclusion}

The geographical analysis of the percentage of African American population distribution in the City of Chicago and its suburban municipalities has discovered significant spatial patterns. Forty-eight percent of the community areas and $21 \%$ of the suburban municipalities have shown the presence of significantly dominant African American populations. These community areas are found on the Southside (i.e., 87\%), Westside (i.e., 13\%) of Chicago, while suburban municipalities in the south, indicating a clear geographical control of the African American settlement pattern in Chicago city. On the other hand, the significantly lower percent African American populations was detected in 39\% of the community areas and $51 \%$ of the suburban municipalities. These suburban municipalities are found in the northern, north western, and western parts of the metropolitan areas. The remaining $13 \%$ of the community areas and $28 \%$ of suburban municipalities didn't show significant spatial patterns of African American population settlement. The 2010 spatial settlement of African American populations has changed from the one in 1990. 
The magnitude of change is higher in the suburban municipalities than in the community areas in Chicago, indicating urban-to-suburban migration of the African American population. In fact, there is a net loss in 51\% of the community areas of Chicago city, while $75 \%$ of the suburban municipalities showed net gain in African American population.

Most of these changes occurred in the areas and municipalities where the percent African American population is low (i.e., $<5-10 \%)$ and very low $(<5 \%)$ in 1990 census. This can be interpreted as a trend of African American movement to predominantly white neighbourhoods, and racial integration thereof.

In general, this study has shown a geographic controlled Black population settlement patterns as well as movement in and between Chicago city and surrounding suburban municipalities. Better jobs, lower cost of housing, education, and crime could be among many factors and yet one could also argue that the growth of white, working class millennials in sprawling areas, is a factor. This study hasn't addressed such specific push or pull factors as to why there has seen a shift in population. Is the number of African-Americans leaving Chicago greater than or equal to the number of whites moving into the city? Again, further analysis would have to happen for these findings to occur.

\section{Acknowledgment}

The authors are grateful to professors Gebeyehu Mulugeta, and Daniel Block of Chicago State University and anonymous reviewers for this manuscript. Additionally, the authors are grateful to the following institutions for providing the main and ancillary data for this study: US Census Bureau, CSU GIS lab, and the City of Chicago GIS portal. Special thanks CSU's GIS laboratory for the software provision and some technical supports.

\section{References}

McMillen, Daniel P. "The return of centralization to Chicago: using repeat sales to identify changes in house price distance gradients." Regional Science and Urban Economics 33, no. 3 (2003): 287-304.

Worldometers.info online "The current world population.", February 09, 2017, http://www.worldometers.info/worldpopulation.

US Census Bureau, US population clock, (2017), http://www.census.gov/popclock/

Population Change and Geographic Mobility in the CMAP Region, Chicago Metropolitan Agency for Planning, 2015.

Eltagouri, M., and Wong, G., "More put Chicago in rearview mirror - Metropolitan area leads U.S. in population loss", The Chicago Tribune, March 23, 2017.

Gee, M., "Another great migration is under way: Black Americans are leaving big cities for the suburbs", The Globe and Mail, 2018.

Anselin, Luc. "Local indicators of spatial association-LISA." Geographical analysis 27, no. 2 (1995): 93-115.

Kunene, N., M. Gella, and T. Gala. "Geographic Controls of Adult HIV/AIDS Prevalence and Their Determinants for Sub-Saharan Africa Countries." American Journal of Public Health 5, no. 4 (2017): 130-137.

Kunene, Nonkululeko Rejoice. "Scaling up Spatiotemporal dynamics of HIV/AIDS Prevalence in sub-Saharan Africa." PhD diss., Chicago State University, 2016.

Layson, Hana, and Kenneth Warren. "Chicago and the Great Migration, 1915-1950." The Newberry, March (2013): $14-15$.

Boustan, Leah Platt. Racial residential segregation in American cities. No. w19045. National Bureau of Economic Research, 2013.

Semuels, Alana. "Chicago's awful divide." The Atlantic 28 (2018).

Colby, Sandra, and Jennifer M. Ortman. "Projections of the size and composition of the US population: 2014 to 2060." (2015)..

Darling-Hammond, Linda. "The color line in American education: Race, resources, and student achievement." Du Bois Review: Social Science Research on Race 1, no. 2 (2004): 213-246.

Hobbs, Frank, and Nicole Stoops. Demographic trends in the 20th century. Vol. 4. US Census Bureau, 2002.

Córdova, Teresa L., and Matthew D. Wilson. "Abandoned in their neighborhoods: Youth joblessness amidst the flight of industry and opportunity." Great Cities Institute, University of Illinois at Chicago (2017).

Mendell, David. "New numbers add up to decade of diversity minority boom, aging population reshape chicago." Chicago Tribune (2001).

Tefera, Adai, Erica Frankenberg, Genevieve Siegel-Hawley, and Gina Chirichigno. "Integrating suburban schools: How to benefit from growing diversity and avoid segregation." (2011). 